\title{
ANTROPOLOGIA DO CINEMA: AS NARRATIVAS CINEMATOGRÁFICAS NA PESQUISA ANTROPOLÓGICA
}

Carlos P. Reyna*

\section{RESUMO}

Já passou mais de setenta e um anos desde que Ruth Benedict nos apresentou sua obra "O Crisântemo e a Espada" (1946), trabalho que, de meu ponto de vista, contempla o nascimento da antropologia do cinema. São sessenta e quatro anos desde que Margaret Mead nos apresentou seu "Estudo de Culturas à Distância" (1953) pela primeira vez; a partir de então tem se realizado muitas pesquisas tomando o cinema como potenciais fontes interpretação nas ciências sociais. Sua integridade e constituição que um dia foram colocadas em questão, hoje ressurgem, sobretudo no ambiente acadêmico, com uma série de propostas que permitem esclarecer e sedimentar teórica e metodologicamente seu horizonte. É por isso, que baseados em nossas experiências e etnografias fílmicas, gostaríamos fazer algumas considerações epistemológicas e metodológicas da utilização das narrativas cinematográficas na pesquisa. Este artigo não entrará em debates e discussões dos novos estudos contemporâneos sobre cultura, não tenho a pretensão de um balanço exaustivo, quanto muito apontarei algumas considerações.

Palavras-chave: Antropologia do cinema. Etnografia fílmica. Epistemologia. Metodologia.

\section{Antropología del Cine: las narrativas cinematográficas en la investigación antropológica}

\section{RESUMEN}

Ya pasaron más de setenta y un años desde que Ruth Benedict divulgó su obra el "Crisantemo y la espada" (1946), trabajo que, desde mi punto de vista, considera el nacimiento de la antropología del cine. Son sesenta y cuatro años desde que Margaret Mead, presentó su obra "Estudio de Culturas a la Distancia" (1953) por primera la primera vez; desde entonces vienen realizándose muchas investigaciones tomando al cine como fuente de interpretación en las ciencias sociales. Su integridad y constitución que un día fueron colocados en duda, hoy resurgen, sobretodo en el ambiente académico, con una serie de propuestas que nos permiten clarear y fundar teórica y metodológicamente su horizonte. Por ese motivo, que basados en nuestras experiencias y etnografías fílmicas, nos gustaría hacer algunas consideraciones epistemológicas y metodológicas del uso de las narrativas cinematográficas en la investigación. Este artículo no abordará debates y discusiones sobre los nuevos estudios contemporáneos sobre cultura, no es mi pretensión de realizar balances profundos, por lo mucho levantaré algunas consideraciones.

PALVAVRAS CLAVE: Antropologia del cine. Etnografia fílmica. Epistemologia. Metodologia.

\section{Anthropology of Cinema: the cinematographic narratives in anthropological research}

\section{ABSTRACT}

It has been more than seventy-one years since Ruth Benedict introduced us to his work "The Chrysanthemum and the Sword" (1946), a work that, from my point of view, contemplates the birth of cinema anthropology. It's been sixty-four years since Margaret Mead introduced us to her "The Study of Culture at a Distance" (1953) for the first time; since then, a lot of research has been done taking cinema as potential interpretation source to social sciences study. Its integrity and constitution, that one day were put in question, rise again specially in the academic environment, with a series of proposals that allow us to clarify and sediment its horizon, theoretically and methodologically. That is why, based on our filmic experiences and ethnographies, we would like to make some epistemological and methodological considerations regarding the use of cinematographic narratives in research. This article will not present any debates or discussions about the new contemporary studies on

* Professor do Programa de Pós-graduação em Ciências Sociais e do Curso de Cinema e Audiovisual da Universidade Federal de Juiz de Fora. Contato: carlos.reyna@uff.edu.br 
culture; I do not pretend to have an exhaustive balance, even though I will point out some considerations.

KEYWORDS: Anthropology of cinema. Film ethnography. Epistemology. Methodology.

\section{PRIMEIROS AFETOS}

Um dos motivos sobre os modos de aparecimento do cinema ao longo da história teve sua origem ligada à pesquisa antropológica. Lembremos um pouco. A antropologia e o cinema têm seu primeiro encontro no ano de 1895 através de dois acontecimentos: o primeiro, Louis-Félix Regnault filmava com um "fusil cronofográfico" do fisiologista Etienne-Jules Marey, registrava uma mulher Wolof fabricando potes de argila na no quadro da Exposição Colonial de Paris. Em dezembro desse mesmo ano, os irmãos Lumiére apresentavam ao público de "Grand Café", em Paris, um filme sobre "A chegada de um trem à estação de La Ciotat". Ambos casos são geralmente identificados como os primeiros filmes com valor etnográfico e documental respectivamente. No caso de LouisFélix Regnault é claro seu propósito voltado para o campo da ciência. Esse estudo foi o primeiro reconhecimento científico sobre detalhes efêmeros do movimento que não são facilmente capturados a olho nu. Já, do filme dos Lumière, acima mencionado, nasce documentário, pois a falta de organização do material profílmico perante a câmara favorece esse significado.

A partir dessa promissora génese, temos muitos pioneiros que utilizaram a imagem animada como meio de documentar o que entendia-se na época como sociedades pouco evoluídas. A realização desses documentários fez deles precursores da transformação dos métodos clássicos de pesquisa antropológica. Entre os mais nomeados e conhecidos, o geólogo Robert Flaherty - considerado o patriarca do filme antropológico, filmou o dia-a-dia do esquimó Nanook (1922). Desde então, têm se realizado muitos filmes e recentemente muitos vídeos que nos mostram e descrevem "outras" culturas. No entanto, só algumas dessas realizações se elaboraram tomando como base aquilo que fez de Nanook uma das principais lições. Juntaramse de alguma maneira duas modalidades culturais para assim poder observar tanto a vida cotidiana quanto os meios derivados de conhecimentos sistematizados. A opção de Flaherty no seu filme foi provavelmente o primeiro passo para a introdução dos meios de comunicação (cinema, vídeo e fotografia) na aquisição de conhecimento antropológico. Conhecimento através do qual tanto os povos que têm enfrentado o desafio que supõe a representação de suas próprias histórias e culturas, quanto dos antropólogos usuários do audiovisual que tentam ou reconstruir culturas no sentido contrário aos processos de aculturação, e divulgar elementos do comportamento tradicional para a posteridade, ou analisar os diferentes fenômenos culturais apoiados nas imagens como fonte reveladora de descoberta antropológica.

Com base nessa génese e nessas experiências, o cinema na antropologia vêm sendo utilizado de diferentes maneiras: como ferramenta e como objeto de pesquisa. Como ferramenta, também denominado de antropologia visual ou filme etnográfico, é utilizado tanto como instrumento de pesquisa nos fenômenos culturais, quanto meio de ilustração e difusão das pesquisas. E, ainda, não esqueçamos, do ponto de vista da introdução no aparelho de pesquisa de diferentes meios tecnológicos, a emergente área denominada de antropologia fílmica, cujos objetivos pretendem, além da produção de filmes documentários, considerar as imagens em movimento como objeto de investigação em primeiro plano. Isto é, essa caracteriza-se por debruçar-se sobre as questões metodológicas subjacentes a qualquer registro fílmico de caráter antropológico.

Já são quase 70 anos desde que André LeroiGourhan (1948, p. 42-50), apresentou seu trabalho intitulado "Le film etnographique existe-t-il?" ao Congrès International du film d'Ethnologie et de Géographie, artigo que contempla o nascimento do filme etnográfico. Mas, a sua integridade e constituição continuam a colocar-se em pauta a discussão assim como o lugar que lhe deve ser atribuído na pesquisa antropológica e na exposição de resultados. Tentar responder tal evidência só será:

Através da exposição de um conjunto de receitas metodológicas é uma tarefa delicada porque ela supõe parcialmente resolvidos 
certos problemas fundamentais. Destes, os mais complexos dizem respeito às funções cognitivas da imagem animada, aos aspectos da vida social e cultural aos quais tem acesso o cinema e às maneiras como se processa este acesso (FRANCE, 1989, p.1).

De tal maneira que não é de surpreender que estes princípios metodológicos do filme etnográfico ainda permaneçam obscuros, não obstante os importantes esclarecimentos trazidos por aqueles que tentaram e continuam a fazer por várias vezes um balanço do emprego do filme etnográfico e de considerar seus novos horizontes.

Contemporaneamente, o que tudo indica, que a pesquisa em antropologia visual não só se limita à utilização do filme etnográfico como método, mas a questão de coleta de dados etnográficos e interpretação antropológica está se originando de outras fontes não etnográficas tais como a internet, televisão e fundamentalmente, diria eu, o cinema documentário e de ficção. Portanto, é necessário entender as procedências, sequências e percursos desses fluxos de informação. Eles são verdadeiros e atuais fontes de produção do sentido, cuja existência nos impõe seu estudo, pois nos apresentam explicitamente representações da cultura.

É nesse sentido que este artigo se orienta. Isto é, o cinema como objeto na antropologia, o cinema como campo de pesquisa, como base empírica, que preliminarmente poderíamos dizer, abordagens culturais e sociais do ponto de vista do espectador, neste caso, do antropólogo que, "diante da imagem fílmica, dedica-se à decifração" (HÍKIJI, 1991, p. 91-113, grifo nosso). Entendemos por decifração à observação e interpretação antropológica.

\section{DO ESTUDO DE CULTURAS À DISTÂNCIA A OS ESTUDOS DE CARÁTER CULTURAL CONTEMPORÂNEOS}

A antropologia tem uma longa experiência sobre o estúdio de culturas à distância. Grosso modo, se inicia no século XIX com antropólogos que consideravam o estúdio do Outro "o selvagem" a partir de uma distância segura. Estes "especialistas" conhecidos como antropólogos de gabinete, valiam-se das narrativas de viajantes e missionários, de relatórios de oficiais e administradores coloniais, de memórias de exploradores e navegantes para entender no que em seu tempo se denominavam de culturas "exóticas" às culturas não ocidentais. A averiguação in situ dos comportamentos nativos ainda mostrava-se breve e superficial em relação ao peso que essas fontes de natureza secundária exerciam. Uma lacuna ainda permanecia em aberto no tocante aos fatos corriqueiros da vida social incapazes de serem acessados por outros caminhos que não seja da observação direta da realidade. A passagem da antropologia de quatro paredes à pesquisa no local/no campo foi realizada graças a Bronislaw Malinowski que converterá o extenso trabalho de campo etnográfico na estratégia de pesquisa definitiva da antropologia enquanto disciplina.

Na busca de encontrar a gênese ou certidão de nascimento entre aquilo que hoje está se chamando de antropologia do cinema ${ }^{1}$ me leva estudar as páginas de pesquisadoras associadas com a antropologia cultural. $\mathrm{Na}$ vanguarda temos Ruth Benedict discípula de Franz Boas considerado fundador da antropologia nos norte-americana. Em 1944, no apogeu da guerra entre o Japão e os Estados Unidos, a "Office(s) of War Information y of Strategic Studies" solicita à Ruth Benedict elaborar um estúdio sobre a cultura japonesa com o intuito de melhor compreender o inimigo. Esse pedido foi motivo para a antropóloga aplicar seus Patterns of Culture $^{2}$ (1934) (2013), seus modelos ou padrões culturais, e tentar desvendar esse "enigmático"

$1 \mathrm{Um}$ artigo muito interessante e pouco divulgado a respeito do percurso que revela a existência de uma pequena história da antropologia do cinema foi publicada pela antropóloga Rose Satiko Gitirana Híkiji. Antropólogos vão ao cinema - observações sobre a constituição do filme como campo. Cadernos de Campo (São Paulo, 1991), São Paulo, v. 7, n. 7, p. 91-113, mar. 1998. ISSN 23169133. Disponível em: <https://www.revistas.usp.br/cadernosdecampo/article/view/52606/56520>. Acesso em: 14 sep. 2017. doi:http:// dx.doi.org/10.11606/issn.2316-9133.v7i7p91-113. 
país ao ocidente. No entanto, pelas próprias circunstâncias e limitações da guerra, o trabalho de campo ficou restrito ao estúdio da produção literária, jornais, dados econômicos e sobretudo, filmes:

(...) filmes que haviam sido escritos e produzidos no Japão - filmes de propaganda, filmes históricos e filmes sobre a vida contemporânea em Tóquio e nas aldeias. Comentamos posteriormente com japoneses que haviam visto alguns desses filmes no Japão e que, pelo menos, viam o herói, a heroína e o vilão como os japoneses o viam e não como eu os via. Quando eu me desorientava, era claro que o mesmo não acontecia com eles (BENEDICT, 1972, p. 14-15).

Os filmes, na citação acima, são referência da cultura japonesa. O método utilizado é muito claro: no visionamento em diferido sobre a imagem fílmica, a antropóloga de maneira compartilhada com seus informantes, de descendência japonesa levantava questões culturais da cultura japonesa. Do resultado desse estúdio "de longe" foi publicado em 1946 o livro "O Crisântemo e a Espada"3 e se converteria em referência sobre a cultura japonesa tanto nos estúdios antropológicos quanto históricos.

Após essa pesquisa fundadora, a Segunda GuerraMundialinterrompeapesquisaetnográfica de muitos antropólogos ao converter amplas regiões do mundo inacessíveis para a pesquisa de campo. Nos Estados Unidos e na Inglaterra, muitos antropólogos oferecem seus serviços às forças aliadas na luta contra Alemanha, Japão e Itália. Ressurge então os estudos de culturas "de longe", desta vez com melhores métodos de pesquisa, maiores conhecimentos etnográficos e mais experiência empírica daquela antropologia de gabinete do século XIX.

O Outro, nesse caso, não era mais ou "selvagem" ou o "exótico" e sim o "inimigo", com tradições culturais diferentes, o governo dos EUA orientou os antropólogos para a introspecção. $\mathrm{O}$ antropólogo, impedido de cumprir a tradicional rotina do longo período de observação participante no campo, devia agora entrevistar imigrantes, analisar produtos artísticos como romances e filmes elaborados em outros países, ou examinar materiais veiculados nos meios de comunicação, com a intenção de aceder a esses universos culturais sempre acompanhados pelo adjetivo nacional. As fronteiras entre países foram traduzidas em termos culturais e as fronteiras culturais definidas em termos nacionais, delineando, assim, os limites das novas unidades de análise.

O resultado foi um esforço de pesquisa que continuaria por muito tempo depois da guerra. Estou me referindo à obra da pesquisadora Margaret Mead" "The Study of Culture at a Distance" ${ }_{5}$ que escreveu em parceria com a antropóloga da área de estudos interculturais Rhoda Métraux em 1953. Este "manual" reúne uma série de artigos de pesquisadores que trabalhavam nos quadros do projeto Research in Contemporary Cultures, conduzido por Ruth Benedict na Universidade de Columbia a partir de 1947. O livro é, na verdade, "uma versão muito condensada de um esboço preliminar apresentado ao Office of Naval Research no outono de 1951" (MEAD \& MÉTRAUX, 1953). Entre os trabalhos reunidos na obra, há pesquisas que têm como material empírico as mais variadas formas de produção cultural; não se trata apenas do uso de testes projetivos (amplamente utilizados por alguns antropólogos desde os anos trinta), mas,

2 A proposta central da obra Padrões de Cultura sustenta a necessidade de partir de um conjunto de traços psicológicos chaves (estilos) ou conceitos podemos descrever e interpretar a cultura de uma sociedade. A autora segue as ideias de Nietzsche e propõe um modelo geral de dois tipos de seres humanos cujos traços psicológicos constituem dois tipos de cultura: os "apolíneos" Pueblo ou os “dionisíacos" Índios das Planícies. Ver Ruth Benedict. Padrões de cultura. Lisboa: Ed. Livros do Brasil, p. 13-32, 2000.

3 A tese do livro O Crisântemo e a Espada (1972), publicada originalmente em 1946, é bem conhecida. A antropóloga baseou sua interpretação antropológica em um tripé crucial e desconhecido até então da cultura japonesa: a visão hierárquica de todos os aspectos da vida; a chamada "cultura da vergonha" (diferente da "cultura da culpa" ocidental) e; o ubíquo peso da honra no cotidiano. BENEDICT, Ruth. O crisântemo e a espada. São Paulo, Ed. Perspectiva,1972 [1946].

4 Margaret Mead é reconhecida, entre outros aportes, pelas suas contribuições na área de antropologia cultural; pela capacidade de abrir e promover pesquisas em diferentes campos, bem como a sua capacidade de criar, transformar e desafiar ideias, preconceitos e pensamentos de seu tempo.

5 Embora a pesquisa tenha ocorrido sob o patrocínio nominal de Ruth Benedict, Margaret Mead foi quem organizou todo o projeto. 
reiteramos, de obras literárias e autobiografias, contos populares, rituais e festas nacionais, cartas de imigrantes, filmes, manuais escolares e de ensino de estratégias do jogo de xadrez.

Um texto escrito por Margaret Mead em 1953 resume notavelmente os pontos mais significativos dos estudos antropológicos sobre caráter nacional:

Os estudos de caráter nacional são um recente desenvolvimento na pesquisa antropológica sobre os problemas de cultura e personalidade. Eles tomam tanto sua forma quanto seus métodos das exigências da situação política mundial após 1939. Ainda que os estudos de caráter nacional utilizem as premissas e os métodos do campo da cultura e personalidade, historicamente apresentaram dois traços distintivos: seleciona-se para estudo a cultura de um grupo de pessoas com uma tradição social compartilhada porque são os cidadãos ou membros - nationals - de um Estado político soberano, sendo que a sociedade pode ser tão inacessível à observação direta no campo que métodos de pesquisa menos diretos têm que ser utilizados. Estes estudos contemporâneos de caráter nacional e de cultura à distância assemelham-se a tentativas de reconstruir o caráter cultural de sociedades do passado (...) onde o estudo de documentos e monumentos teve que ser substituído pelo estudo direto de indivíduos interagindo em situações sociais observáveis. Entretanto, eles diferem da reconstrução histórica na medida em que, sejam eles feitos à distância ou através de trabalho de campo na nação considerada, estão primordialmente baseados em entrevistas e observação de seres humanos vivos (MEAD, 1953, p. 396).

Algumas considerações podemos tirar dessa citação. A primeira, já sabida, sustenta explicitamente ter sido a situação de guerra o que teria provocado, ou, ao menos, favorecido, as diferentes formulações sobre o conceito de caráter nacional. Segunda, determina as "nações" como unidades de análise dessas investigações. Por último, sobre o pano de fundo das duas primeiras, surgia a imposição de uma "adaptação" metodológica: os "estudos de cultura à distância".
No entanto, o "manual" para estudar "culturas à distância", Margaret Mead, além de apresentar os primeiros pressupostos metodológicos que descrevem métodos de pesquisas interdisciplinares e, de meu ponto de vista, uma proposta subliminar para os antropólogos colocar o filme no centro de suas atenções e pesquisas, nos diz, paradoxalmente que, os "estudos de cultura à distância" não necessariamente têm relação privilegiada com a distância, vejamos no capítulo 1:

Ao fazê-lo, presume-se que o Manual não é para uso em isolamento, mas é bastante complementar para um aprendizado de treinamento para estudantes que trabalham juntos ou sob supervisão. A partir dele, o aluno deve ser capaz de aprender, não exatamente como realizar um conjunto de entrevistas, mas quais entrevistas desse tipo são semelhantes e quais entrevistas podem produzir resultados frutíferos (...) $\mathrm{O}$ material sugere como analisar filmes, mas não os passos particulares ou temas específicos a pesquisar e sim a literatura que pode estar relacionada a outros tipos de material. Isto pode ser sugestivo e estimulante para o aluno construir ... um modelo de adaptação flexível para o carácter único de cada corpo de material cultural. (MEAD, 1953, p. 6, grifo nosso).

Ainda Margaret Mead concebe o "estudo das culturas à distância", envolvendo quatro estágios:

1. Um estágio exploratório em que as hipóteses são desenvolvidas; 2 . Um estágio confirmatório em que as hipóteses são testadas; 3. Um estágio de quantificação onde os métodos de amostragem são utilizados para estabelecer "relações proporcionais" dentro de materiais culturais ou entre membros ou grupos em uma sociedade; 4 . Um estágio de verificação experimental em que as experiências são confrontadas com as hipóteses e as relações proporcionais podem ser quantificadas (Ibid., p. 7).

No entanto, tudo indica que a obra está mais interessada com o primeiro estágio desses procedimentos, o desenvolvimento das hipóteses: 
Neste primeiro estágio exploratório, o tipo de material utilizado é muito menos importante do que a simpatia entre o pesquisador e o tipo de material. A atenção também deve estar focada ao uso específico que um pesquisador de uma determinada predisposição, hábito de trabalho e base disciplinar fará dos informantes, da análise de filme ou qualquer outro material (Ibid., p. 7).

Sobre o mencionado cabe a seguinte reflexão heurística: é interessante observar que as técnicas e os alinhamentos interpretativos das citações precedentes são exatamente aquelas utilizadas na antropologia contemporânea quando esta investiga as sociedades "nacionais" ("modernas" ou "complexas"), especialmente, quando o antropólogo faz parte da sociedade que está investigando. Portanto, a não utilização das técnicas de observação participante parece estar muito mais ligada a propriedades do objeto isolado como unidade de análise - ou às relações entre este objeto e o investigador, que se caracterizam exatamente por sua proximidade - do que a uma suposta impossibilidade de ter acesso direto a ele. Isto é, não foi preciso, esperar que "cultura e personalidade" se convertesse em "caráter nacional" para que a sociedade à qual pertence o antropólogo viesse a se tornar seu grande foco de interesse. Tanto os trabalhos de Mead e Bateson sobre Bali quanto os "padrões de cultura" isolados por Benedict, atestam que o modelo do caráter nacional não exige nações, como não exige distância, para ser aplicado. Sobre o emprego de técnicas especiais de pesquisa ou os "estudos de cultura à distância", Neiburg \& Goldman nos confirmam isso:

$\mathrm{Na}$ verdade, a proposta dos "estudos de cultura à distância" como método privilegiado para o trabalho antropológico com as "nações" encerra um paradoxo, na medida em que os antropólogos são, sempre, membros de estados nacionais, portanto, muito mais "próximos" desse objeto do que daquele sobre o qual a antropologia tradicionalmente trabalhara (2002, p. 66-67).

Pelo exposto, os "estudos culturais à distância" que bem poderíamos chamá-lo por um termo mais geral de "estudos de caráter cultural" ou "estudos contemporâneos de cultura", não tem "relação privilegiada" com a distância e sob os procedimentos interpretativos do Geertz - que veremos mais adiante -, podem ser conduzidos em qualquer tipo de sociedade ou cultura.

\section{O "REALISMO" NO CINEMA E SUAS REPRESENTAÇÕES SOCIAIS.}

Para o âmbito da antropologia do cinema nos interessa aqui saber como o cinema funciona tanto como meio de representação da realidade quanto referência cultural? Ambas não são excludentes, pelo contrário, para fundar algumas bases de uma proposta epistemológica que assuma o cinema como fonte de conhecimento ou objeto de pesquisa, são necessários algumas interações e diálogos com a antropologia e a sociologia e, sobretudo, com a própria linguagem cinematográfica entre outras disciplinas.

A reflexão de como opera a relação filmeespectador a questão do "realismo" no cinema está vinculada à natureza única da imagem. Isto é, a sua capacidade de reproduzir tecnologicamente, de maneira exata, a realidade. Como isto funciona? Segundo dois teóricos do cinema Siegfried Kracauer e André Bazin nos dão substratos para seu entendimento. Em sua Theory of film (1960) Kracauer nos diz o que mais interessa no cinema é o conteúdo, pois ele nos apresenta a vida como ela é. Pois são o conteúdo e o fluxo da vida do tema meios de transmitir ideias, emoções e valores. Certamente, as questões de técnica e estilo devem estar vinculadas e em sintonia a realidade apresentada. É, dessa maneira, que a relação filme-espectador funciona. Segundo o autor, as imagens em movimento pela sua proximidade com a verossimilhança (impressão da realidade) cotidiana seduz e cativa o espectador levando-o ao interior do filme. Por esse motivo, o filme é um elemento útil para recolher a emoção do mundo, expressando as relações que podem se estabelecer entre as coisas e os homens, entre o espaço e o indivíduo. Essa experiência exige interpretação e análise.

Se para Kracauer o cinema só é a realidade dos fatos, para Bazin existe uma dependência do cinema à realidade a tal ponto de nos dizer que o cinema é arte do real. No esforço de esclarecer 
o que entende por realismo, o autor da obra "O Cinema" (1991) em seu capítulo sobre a "ontologia da imagem fotográfica" nos apresenta motivos de contiguidade com a imagem. A gênese automática da fotografia e do cinema são testemunhos e provas de existência das coisas do mundo:

A originalidade da fotografia com relação à pintura reside em sua objetividade essencial. Tanto é que conjunto de lentes que constitui o olho fotográfico em substituição ao olho humano denomina-se precisamente 'objetiva'. Pela primeira vez, entre o objeto inicial e sua reinterpretação nada se interpõe, a não ser um outro objeto. Pela primeira vez, uma imagem do mundo exterior se forma, automaticamente, sem a intervenção do homem, segundo rigoroso determinismo (1991, p. 22).

\section{Como diria Roger Munier (apud DUBOIS,} 1993, p. 33) "a fotografia é o apagamento total diante do real com o qual coincide. É o mundo tal como ele é, em sua verdade imediata, seja ela reproduzida no papel ou na tela". Essa reprodução da "verdade" viria a confirmar a objetividade e essência da fotografia em Bazin, por conseguinte, essa credibilidade é tal que até consegue subverter à psicologia da imagem. De um modo geral, para Bazin, o principal atributo do cinema é que uma arte vinculada à materialidade do registro fotográfico, isto é, à característica de realizar um registro conclusivo e irrefutável da realidade. Sobre isso, é necessário mencionar um diálogo com a obra "A autoridade etnográfica" (1998) de Clifford James na antropologia. O autor demostra que a noção de autoridade etnográfica, isto é, um dos modos como ele legitima um discurso sobre a realidade é que através do famoso "eu estive lá" que a fotografia dá evidência de que o que pesquisador viu existe e o que ele diz é verdadeiro.
A respeito disso, é bom lembrar também de Os Argonautas do Pacífico Ocidental (1976) do Bronisław Malinowski como um ponto de inflexão na pesquisa de campo na antropologia, pois a obra incorpora 65 pranchas (totalizando 75 fotografias).

Sobre a semelhança com a realidade concordo com Phillipe Dubois (1993) quando nos diz que a ontologia da fotografia não está no mimetismo, mas no princípio de uma transferência das aparências do real para a película sensível. Isto é, a matéria prima do cinema não é a real tal qual, mas os traços dela na celuloide. Esses traços me parecem importantes, sobretudo pelo seguinte motivo, vejamos: por ser em sua gênese automática ligada à realidade eles são compreensíveis, por tanto interpretados. O mundo tem deixado um traço de si mesmo no cinema e o cinema torna visível o mundo. Certamente, talvez não seja correto falar de "realidade" para aquilo que o cinema nos dá a ver, mas o próprio Bazin utiliza o termo emprestado da geometria, para mencionar que o cinema é uma assímptota da realidade ${ }^{6}$, isto é, cada vez que o cinema se aproxima dela mais dela depende.

Embora o grande debate do realismo continue presente, o cinema continua vinculado e ancorado tanto à produção do registro fílmico ${ }^{7}$ e à construção do tempo quanto à percepção e às funções de seu discurso hermenêutico e interpretativo que se abre livremente para a imaginação ${ }^{8}$ nas ciências sociais. Então, daquilo que foi mencionado, se esboça uma verdadeira antropologia à luz do cinema ou antropologia do cinema.

6 A introdução do som é também outro componente tecnológico que reforça a ideia da ilusão de realidade.

$7 \mathrm{O}$ avanço das tecnologias digitais de produção e tratamento de imagens tem desafiado seriamente as reflexões tradicionais sobre a fotografia e o cinema. De maneira geral, as teorias clássicas destes meios às definem pela capacidade de proporcionar automaticamente, inclusive de forma necessária, uma imagem verdadeira daquilo que esteve diante da câmara no momento que o obturador fez o clique. Jean Luc Godard já nos dizia, o cinema é vinte quatro fotogramas por segundo. Será que essas teorias clássicas continuam sendo adequadas e relevantes? O fundamental aqui está na identificação que o espectador faz da trama do filme, independentemente de ser analógico ou digital. O espectador participa da cena graças à capacidade da chamada "teoria do espirito". Segundo Jullier e Marie (2009) "Ela consiste, para ele, de imaginar - de modo a poder agir em consequência disso - o que as pessoas que ele olha sentem e em que elas pensam, baseado no que ele próprio sente e pensa (porque não se pode conhecer senão um único espírito, o próprio)”. É isso o que permite aprender, se comunicar e viver em sociedade. Lendo as imagens do cinema, São Paulo; SENAC, 2009, p.68 
O CINEMA COMO OBJETO NA ANTROPOLOGIA

Ao apresentar o campo da antropologia do cinema, é necessária uma primeira observação: fica cada vez mais clara que a perspectiva estética do cinema e a exploração etnográfica na antropologia, longe de serem excluídas, estão ligadas por implicações mútuas. Então, quais explorações heurísticas nos permitem tratar o cinema como um poderoso agente e objeto de estudo na antropologia. Por estranho que possa parecer, o que resulta é um conjunto de abordagens férteis que não se restringem exclusivamente ao dispositivo e suas criações, as imagens, mas, entender o próprio cinema como um meio específico de produzir e reproduzir significação cultural. Particularmente, acredito inicialmente, que temos um duplo percurso possível: imagético e metodológico.

O primeiro, imagético, que abordagem nos permite tratar o cinema como representação cultural e objeto de interpretação nas ciências sociais ou ferramenta de analises cultural contemporânea? Como deve ser entendido? Será necessário assumir as propostas de monumento ou objeto de montagem em Sergei Eisenstein (1990) ou objeto de ciência em Aby Warburg (Didi-Huberman, 2006). De que maneira orientar-nos? Como máscara que encena uma narração a respeito de seu significado? Como a linguagem que fala, não o autor, em Barthes (1988) ou, pelo contrário, mergulhar no discurso do autor segundo Michael Foucault (2011).

Para poder fundamentar esta primeira exploração são necessárias interações com outras áreas das ciências sociais, notadamente, a sociologia. O primeiro diálogo refere-se a um itinerário construído por Pierre Francastel ${ }^{9}$, historiador e pensador da sociologia da arte. Sua relação com o cinema está vinculada com a concepção da natureza da imagem e, sua aproximação com a arte o leva a questionar as mudanças na percepção causadas pelo surgimento da fotografia e cinema. $\mathrm{O}$ autor menciona que "Os aparelhos penetram o real: graças à câmera, temos possibilidades que não existiram [anteriormente] de descobrir um certo número de elementos que são reais, mesmo antes da projeção, que não foram criados pelo filme." (Apud ALBERA, 2009, 291). Isto é, "os dispositivos ao penetrarem a realidade" mudam as condições de percepção e representação, destacando como nunca antes o caráter cultural e convencional da imagem. Diferente das imagens mentais, plásticas, poéticas ou literárias, a imagem fílmica, vinculada ao seu aparelho de criação (fabricação), "faz com que o filme apareça dotado de realidade, persuasão, verdade ou pelo contrário, inaceitável. [Assim] o filme é, ao mesmo tempo, uma coisa fabricada, é um médio e, por outra parte, é um registro automático, mecânico do real". (FRANCASTEL,1983, p. 59).

Em outras palavras, a imagem fílmica, não é uma imagem natural, imediata, "duplo", ele é um signo e está inscrito em um sistema de signos, cujo estágio final da imagem fílmica é de natureza mental que seria a "a soma das impressões experimentadas por um espectador a quem se apresenta uma sucessão de imagens que são seus elementos constituintes." (FRANCASTEL, 1983, p.11-12). O autor ainda reforça esse espírito ao caráter alusivo das imagens quando nos diz: "A imagem existe em si mesma; ela existe essencialmente no espírito, como uma referência de cultura e não como referência de realidade (Ibid., p. 193). Essa sucessão de imagens e seus

8 Foi o sociólogo norte-americano Wright Mills (1916-1962) quem propus há 58 anos entender a imaginação sociológica como a capacidade que todo indivíduo tem para compreender sua própria experiência e avaliar seu próprio destino situando-se ele mesmo em sua época. A imaginação sociológica está constantemente submetida aos desafios que a experiência humana enfrenta em cada período histórico. A imaginação sociológica. 2a Edição. Rio de Janeiro: Zahar Editores, 1969. Ainda sobre a imaginação Etienne Samain nos lembra que Warburg (1866-1929) teria dado razão a Baudelaire (1821-1867) quando lembrava que a imaginação é uma potência do pensamento comum ao poeta e ao sábio; nesses termos: "A imaginação é uma faculdade quase divina que percebe primeiro - fora os métodos filosóficos - as relações íntimas e os segredos das coisas, as correspondências e as analogias. As honras e as funções que [Edgar Poe] confere a esta faculdade lhe dão um valor tal [...] que um sábio sem imaginação não passa de um falso sábio ou, pelo menos, de um sábio incompleto." Ver texto do Etienne Samain em As "Mnemosyne(s)" de Aby Warburg: Entre Antropologia, Imagens e Arte. Revista Poiésis, n 17, p. 29-51, jul. de 2011.

9 Ver importante artigo de Paulo Menezes. Representificação: as relações (im)possíveis entre cinema documental e conhecimento. Rev. bras. Ci. Soc. [online]. 2003, vol.18, n.51, pp.87-98. ISSN 1806-9053. http://dx.doi.org/10.1590/S0102-69092003000100007. Ler também neste número o texto "Sociologia e Cinema: aproximações teórico-metodológicas" do mesmo autor.

10 François Albera "Pierre Francastel, le cinéma et la filmologie." Cinémas 192-3 (2009): 287-316. DOI: 10.7202/037557ar 
elementos constituintes deslocados de sua própria realidade ou de qualquer registro exterior servem como modelo e referência dos valores culturais da sociedade na qual foram criadas.

Modelos e referências reflexos de uma sociedade definidas por Graeme Turner na sua obra "Cinema como prática social". Nele o autor nos diz que existe uma rua de mão dupla cujo feedback entre o cinema e o meio cultural é constante:

O cinema não reflete nem registra a realidade; como qualquer outro meio de representação, ele constrói e "re-apresenta" seus quadros da realidade por meio dos códigos, convenções, mitos e ideologias de sua cultura, bem como mediante práticas significadoras específicas desse meio de comunicação. Assim como o cinema atua sobre os sistemas de significação da cultura - para renová-los, reproduzi-los ou analisá-los - também é produzido por esses sistemas de significado (1997, p. 128-129).

Cabe aqui nos perguntar, quais representações veicula esse discurso fílmico? Sabemos que o filme será sempre produzido por estruturas profundas, ligadas ao exercício da linguagem fílmica e a sua organização simbólica. Esta última, é mecanismo pelo qual a cultura e a sociedade produz e reproduz os seus significados sociais, ou seja, um meio de representação e reflexão do mundo.

Nesse sentido, é necessário voltarmos para o livro que consideramos para nossos propósitos, muito atual, publicado em 1956. Estamos nos referindo ao ensaio de antropologia sociológica "O Cinema ou o Homem Imaginário" de Edgar Morin. A obra de inspiração antropológica é amplamente apoiada pela abordagem teórica do cineasta Jean Epstein e pelas pesquisas realizadas na França, pelo l'Institut de Filmologie (1948-1963) $)^{11}$. Morin tenta reformular a divisão tradicional, impermeável, entre real e imaginário, onde o cinema é considerado um objeto privilegiado para estudar os fenômenos de "interesses imaginários". "La objetividad del mundo del cine necesita de nuestra participación personal para para tomar cuerpo y esencia (...) Este mundo necesita de nuestra sustancia para vivir" (2001, p. 134). Morin utiliza a magia como modelo de referência em seu livro. Melhor dizendo, em sua obra sempre elabora a distinção entre o "cinematógrafo", dispositivo de gravação do movimento visível, a "fotografia animada" e o "cinema", superação expressiva e artística da técnica inicial produzida pelo trabalho do imaginário (particularmente, do espectador). $\mathrm{O}$ universo mágico é determinado por:

El film a escala del plano, como a escala del conjunto del montaje, es un sistema de ubicuidad integral que permite transportar al espectador a cualquier punto del tempo y del espacio. Observemos que no se mueven ni el espectador así transportado ni la pantalla, son los objetos que se mueven sobre la tela según los avances, retrocesos y saltos de la cámara. Aparecen y desaparecen, se dilatan y se contraen, pasan de lo microscópico a los macroscópico y así el efecto óptico de la ubicuidad es la metamorfosis de los objetos (MORIN, 2001, p. 62).

Com essas caraterísticas constitutivas do universo do cinema, o mundo é refletido no espelho do cinematógrafo. E, o cinema nos oferece uma reflexão, não só do mundo, mas do espírito humano. Então, se temos o cinema como mecanismo pelo qual a cultura e a sociedade produz e reproduz os seus significados sociais, ou seja, um meio de representação e reflexão do mundo, só nos resta saber ter acesso a ela. Jacques Aumont reforça esses entrecruzamentos quando nos diz que, para a abordagem do ponto de vista do espectador das imagens, urge a necessidade de "um estudo da imagem fílmica em sua relação com o homem em geral" (1993, p. 130, grifo nosso), pois a diversificação de “(...) o valor dessa tentativa demonstra uma vez mais

11 Ver o número da revue Cinémas, "La filmologie, de nouveau”, sob a direção de François Albera e Martin Lefebvre, volume 19, numéro 2-3, 2009. Notamente os artículos de Jean-Marc Leveratto, "La Revue internationale de filmologie et la genèse de la sociologie du cinéma en France", pp. 183-215. O artigo discute a diversidade das redes científicas e os tipos de investimentos intelectuais que motivam o surgimento de um discurso sociológico sobre cinema. Ele analisa a ancoragem da "sociologia do cinema" defendida por Georges Friedmann e Edgar Morin no contexto epistemológico da sociologia francesa pós-Segunda Guerra Mundial e, em particular, na reinterpretação antropológica da herança Durkheimiana de Marcel Mauss, e o texto de Leonardo Quaresima, "De faux amis: Kracauer et la filmologie", pp. 333-358. https://www.erudit.org/fr/revues/cine/2009-v19-n2-3-cine3099/. 
a dimensão antropológica e social dos estudos cinematográficos, e sua necessidade de entre cruzá-los com as Ciências Sociais." (Id., 2012, p. 292).

\section{ETNOGRAFIAS FÍLMICAS}

Observar e descrever são ações inerentes a toda prática antropológica, sobretudo nos moldes da práxis clássica. Com a introdução das novas propostas imagéticas - o cinema, neste caso - as possibilidades de enriquecer e incrementar outro exercício além destas duas técnicas, revolucionaram o método empírico natural dirigido a revelar e explicar as características observáveis dos fatos culturais. Essas particularidades pressupõem determinadas operações práticas, tanto com os objetos estudados quanto com os meios materiais de apreensão de conhecimento utilizados.

Destas práticas - observar e descrever julgava-se ter dito tudo. A partir de 1969, após numerosos exames e realizações de filmes, Claudine de France $^{12}$ levanta interrogações, questões, opções e dificuldades de ordem metodológica que, na antropologia do cinema, permaneciam obscuras, ainda que existissem aportes teóricos metodológicos efetuados por diferentes pesquisadores usuários da imagem animada. Dos resultados destas análises, a autora entra num terreno importante a ser desvendado, sobretudo no que diz respeito à utilização do filme como meio de obter conhecimento na antropologia. Com o intuito de propor certas considerações de rigor metodológico ela parte da seguinte interrogação "sobre os aspectos da atividade humana os mais acessíveis à imagem animada e sobre os meios específicos à disposição do etnólogo-cineasta para mostrá-los ou colocálos em relevo, fomos levados a nos colocar a seguinte questão: até que ponto a introdução do cinema na etnologia modificou a maneira que tinha o etnólogo de observar e descrever?" (FRANCE, 1989, p.3).

Sabemos que em todo processo de observação podem ser reconhecidos basicamente cinco componentes: $\mathrm{O}$ objeto de observação (o observado); o sujeito de observação (o observador); as condições de observação (contexto natural ou artificial do fenômeno social); os meios de observação (sentido de visão e as ferramentas visuais, [filme, fotografia, etc]) e; o sistema de conhecimentos. Tanto o objeto, quanto o sujeito de observação são elementos imprescindíveis para que esta se realize; não há observação sem objeto quanto menos sem sujeito. Por outra parte, as condições de observação se constituem nas circunstâncias através das quais esta se realiza; quer dizer, o contexto natural ou artificial no qual o fenômeno social se manifesta ou se reproduz. Por sua vez, o sistema de conhecimentos onde se demarca o processo de observação, é o corpo de conceitos, categorias e fundamentos teóricos da antropologia.

No entanto, são os meios materiais de observação - neste caso, o filme - que possibilitam a ampliação, a transformação das qualidades, as características e/ou as particularidades do objeto da observação: o homem e a imagem do homem. O filme, não só na construção estética, mas, sobretudo, se apropriando do seu discurso social e simbólico do objeto/fenômeno representado. Isto é, o fato de ter o mundo refletido no espelho do cinematógrafo, permite tanto o pelo pesquisador, pelo informante e pelos dois juntos, no laboratório, inúmeras vezes, torna-se fundamental para novas etnografias, aqui o passo a chamar de etnografias fílmicas. Isto é, estudos, decifrações e interpretações de filmes em sua relação com o homem, tal qual como aparece no filme, da maneira como Claudine de France nos ensina: "o estudo do homem pelo filme significa não somente o estudo do homem filmável (...) mas, igualmente, o homem filmado, tal como aparece colocado em cena pelo filme" (FRANCE, 2000 , p. 18). A abertura de uma nova relação de troca de informações, graças à presença do filme dá origem a uma nova proposta - a pesquisa exploratória - na antropologia do cinema: "O filme abre a pesquisa.” (Id., 1989, p.309). Isto é, estudos, decifrações e interpretação de filmes em sua relação com o homem, tal qual como é aparece colocado em cena pelo filme. Grosso modo, tomando o filme como campo de pesquisa,

12 Da Formação de Pesquisadores Cinematográficos da Universidade de Paris X - Nanterre sobressai notadamente, a obra Cinéma e Antropologie (1989), de Claudine de France. 
nossa proposta é fazer etnografias fílmicas.

Como a antropologia do cinema está interessada nessas etnografias fílmicas, nos apoiaremos por três frentes da linha interpretativa na antropologia de Clifford Geertz. Vejamos $a$ primeira frente, sobre o conceito de "cultura" nos diz: "o homem é um animal amarrado à teias de significado que ele mesmo teceu, assumo a cultura como sendo estas teias e sua análise, portanto, não como uma ciência experimental em busca de leis, mas como uma ciência interpretativa, à procura do significado" (GEERTZ, 1989, p. 15). Essa metáfora propõe a cultura como um texto, ou um conjunto de textos, que os atores sociais leem e se vem para interpretar o curso dos acontecimentos sociais.

Segunda frente, interpretações de primeira mão. Quando falamos que são os próprios sujeitos sociais que interpretam em primeira mão sua própria cultura, nos estamos referindo ao capítulo destinado a "Pessoa, tempo e conduta em Bali”, na Interpretação das Culturas (GEERTZ, 1989), e o ensaio "Do ponto de vista dos nativos: a natureza do entendimento antropológico" na obra “O Saber Local” (Id., 1997), o autor dá-nos a conhecer uma abordagem antropológica singular desde o ponto de vista dos informantes. Diferente do pesquisador semicamaleão Malinowski, o qual graças a algum tipo de sensibilidade quase sobrenatural pensa, sente e percebe o mundo como um nativo, Geertz insiste em uma questão epistemológica, isto é, na necessidade de os antropólogos verem o mundo do ponto de vista dos nativos. Para isso, Geertz (1997) utiliza os conceitos de "experiência próxima" e "experiência distante", para definir a relação entre o sujeito (pesquisador) e o objeto (informante). Assim, "experiência próxima" é "aquela que alguém - um paciente, um sujeito, em nosso caso um informante - usaria naturalmente e sem esforço para definir aquilo que seus semelhantes veem, sentem, pensam, imaginam, etc., e que ele próprio entenderia facilmente, se outros o utilizassem da mesma maneira". E "experiência distante" como "aquela que especialistas de qualquer tipo - um analista, um pesquisador, um etnógrafo, ou até um padre ou um ideólogo - utilizam para levar a cabo seus objetivos científicos, filosóficos e práticos". Isto é, existe um claro grau de diferenciação entre aquilo que se vê, percebe e significa para o informante (objeto da pesquisa) e aquilo que se vê, percebe e significa para o pesquisador (sujeito da pesquisa). No entanto, como essa diferença não é normativa, um dos conceitos não é necessariamente melhor que o outro, menos ainda é correto preferir um ao outro.

A verdadeira questão, no caso dos "nativos", é que não é necessário ser um deles para conhecêlos. Para saber como as pessoas se representam para si mesmas e para os outros é necessário adotar uma abordagem metodológica que evolua por meio do diálogo entre intérprete (pesquisador) e um seu outro (informante). A partir dessa troca de informações, procurar e analisar, na tela, as formas simbólicas observáveis (manifestas ou encobertas) dos outros com relação à sua própria concepção. Assim sendo, a Antropologia Interpretativa torna-se uma via de acesso quando o autor manifesta que o que está em jogo é de tornar os fenômenos culturais como "símbolos interpretáveis", e não como demonstrativos de código e leis. A análise de Geertz recai sobre a mensagem que o fenômeno cultural transmite, e não no código sobre o qual se organiza a mensagem. Neste sentido é que "casos e interpretações", no filme, estarão privilegiados, pois se supõe aqui o acesso a significação. Aqui proponho o filme como uma teia de significados, texto audiovisual, em se propõe uma análise que interprete os significados para sujeitos e atores sociais da ação. Isto é, uma reflexão e interpretação das representações culturais desse homem por meio da imagem. Portanto, justificase que a antropologia do cinema tem por objeto a imagem do homem tanto quanto o homem.

Terceira frente, interpretações de segunda mão. O autor nos dá "o senso comum como um sistema cultural". Entre as "quase-qualidades" do senso comum Geertz nos menciona a "literalidade", para aquela:

Vocação que o bom senso tem para ver e apresentar este ou aquele assunto como se fossem exatamente o que parecem ser, nem mais nem menos (...) os fatos que realmente importam na vida estão espalhados pela superfície, e não escondidos dissimuladamente em suas profundezas. Não é preciso, e mais, é um erro fatal, negar a obviedade do óbvio (1997, p. 135). 
O saber do senso comum é um conhecimento que está arraigado nas mais variadas culturas "na forma de epigramas, provérbios, obter dita, piadas, relatos, contes morals - uma mistura de ditos gnômicos (...) ditos espirituosos mais trabalhados, como à la Wilde, versos didáticos à la Pope, ou fábulas com animais à la Fontaine" (GEERTZ, ibid, p. 137), e sugerimos tanto o jogo de sombras do teatro de marionetes oriental que tornou possível a realidade cinematográfica e bem como o próprio cinema. O bom senso se constitui, ao mesmo tempo e com a mesma legitimidade, com que se constitui a cultura de uma determinada sociedade. Como construção social depende do contexto, do tempo, do lugar e se expressa de forma natural, portanto, o senso comum deve ser considerado categoria eficaz de tradução de culturas.

Se a cultura é um texto, o papel do antropólogo é interpretar esse texto, penetrar em suas emaranhadas estruturas significativas, compreendendo não apenas o que significa, mas como faz sentido, como ganha significado para os sujeitos sociais. A Antropologia passa a ser considerada não mais uma ciência experimental em busca de leis, mas uma ciência interpretativa à procura do significado.

O antropólogo é visto então como um intérprete, um tradutor cultural. Ele interpreta o fluxo do discurso social: falas, silêncios, gestos, ações. Como intérprete, cabe-lhe traduzir os significados culturalmente construídos pelos sujeitos sociais. Mas vale lembrar que, para Geertz, o antropólogo constrói interpretações de segunda mão, ele interpreta interpretações, lê o texto cultural por sobre o ombro dos nativos. A rigor, são os próprios sujeitos sociais que interpretam em primeira mão sua própria cultura. Mas, como procede o antropólogo para interpretar uma cultura? A resposta pode ser encontrada no programa da antropologia hermenêutica formulado por Geertz. Se a cultura é uma coleção de textos que os indivíduos escrevem, reescrevem e leem em suas interações cotidianas, $\mathrm{o}$ antropólogo deve tomar parte nessas interações para interpretar esses textos, o que não significa virar um nativo, mas aprender a viver com - e não como - eles, sendo de outro lugar e tendo um mundo próprio, diferente (GEERTZ, 1997). Segue daí a centralidade do trabalho de campo etnográfico na Antropologia professada e praticada por Geertz. E fazer Etnografia, diz-nos ele, é como tentar ler um manuscrito desbotado, cheio de rasuras e emendas.

A antropologia do cinema se alinha ao espírito do texto acima mencionado e propõe a etnografia fílmica como seu método. Isto é, sob a "leitura" da tela e/ou no visionamento das imagens, construir interpretações, sempre provisórias, sempre passíveis de serem questionadas e/ou reconstruídas. Como mencionamos no início do artigo, o cinema como base empírica, que desde o ponto de vista do espectador, neste caso, do antropólogo que, diante da imagem fílmica, dedica-se à etnografia e à decifração. Entendemos por decifração à observação e interpretação antropológica de primeira mão e segunda mão, como nos ensina Geertz.

\section{ALGUMAS CONSIDERAÇÕES FINAIS}

Hoje, a comunidade científica nas ciências sociais reconhece que a realidade social é construída de representações que fazemos dela, essas representações, em certo sentido, também participam de nossa percepção da realidade. Isto é, tomando como exemplo Geertz e seu modelo textualístico da cultura (Interpretações da cultura) quando define a "cultura é um texto", nos diríamos também que a "realidade é um texto". As imagens, nessa lógica, são textos que representam a outro texto, a realidade. O cinema, assim como as outras artes, não é realidade, mas fazem parte dela, portanto, a partir desse reconhecimento é que surge nossa aproximação. Tempo e espaço fílmico onde possamos analisar "símbolos interpretáveis" que correspondam à disciplina antropológica. Assim como Geertz do lado da antropologia nos oferece vias de acesso à significação da realidade, do lado do cinema temos, à guisa de exemplo, Roberto Rossellini que reforça nossa proposta quando diz: "o importante é oferecer às pessoas elementos para que possam compreender". Essa declaração sobre a atividade cinematográfica, Rossellini nos oferece uma forte implicação da face compreensiva da antropologia interpretativa do Geertz.

Se a imagem existe como uma referência de cultura (FRANCASTEL, 1983) e, na sucessão de imagens e seus elementos constituintes 
deslocados de sua própria realidade ou de qualquer registro exterior servem como modelo e referência dos valores culturais da sociedade, assumimos que o cinema cumpre funções hermenêuticas e reconhecemos o filme como produtos de significados cujo objetivo é "o estudo de fenómenos sociais totais que pretende integrar todo fato social no grupo na qual se manifesta" (AUMONT e MARIE, 2004, p. 274). Abre-se, portanto, um espaço para a interpretação e o debate antropológicos.

Nesse sentido, nossa aproximação com o cinema vai direcionada à percepção do discurso da obra. Não como uma obra de arte, mas um objeto simbólico que vai além do puramente cinematográfico, seu valor não serve só como testemunho, mas pela aproximação simbólica, social e histórica que permite. Isto é, além de seu conteúdo material que o define como simbólico, o seu significado varia de acordo com os contextos onde foi apreendido. Objeto simbólico, também, fundamentalmente definido pela trajetória ou movimento que o anima. Em cada etapa de sua jornada, seu significado se move, transforma-se, às vezes muda, é também da totalidade desses deslocamentos que constitui seu valor simbólico.

A respeito disso, temos que lembrar novamente o sociólogo Pierre Sorlin. O autor, nos autoriza quando diz que para analisar essas obras temos de considerar:

las películas - una por una, o por grupos, en su globalidad-, como prácticas significantes; estudiarán sus mecanismos, pero tratarán de no aislar nunca su funcionamiento en relación con la configuración ideológica o al medio social en el cual se insertan; haciendo intervenir semiótica y sociología $e$ antropológica, se esforzarán por tener en cuenta los modos posibles de articulación entre expresiones ideológicas y campos sociales. (1985, p. 50, grifo nosso)

Perante o mencionado até aqui, surge a seguinte pergunta, quais requisitos deve cumprir um filme como discurso antropológico? Neste primeiro intento, tentarei me posicionar en passant sobre uma de suas possibilidades. Tanto a antropologia quanto o cinema bebem da mesma fonte, o conhecimento do Outro. Vejamos, para além dos conceitos e definições vejo a antropologia como a ciência do estranhamento, "estranhar" o Outro. Certamente nos estamos referindo ao conceito de alteridade:

A experiência da alteridade (e a elaboração dessa experiência) leva-nos a ver aquilo que nem teríamos conseguido imaginar, dada a nossa dificuldade em fixar nossa atenção no que nos é habitual, familiar, cotidiano, e que consideramos "evidente". Aos poucos, notamos que o menor dos nossos comportamentos (gestos, mímicas, posturas, reações afetivas) não tem realmente nada de "natural". Começamos, então, a nos surpreender com aquilo que diz respeito a nós mesmos, a nos espiar. O conhecimento (antropológico) da nossa cultura passa inevitavelmente pelo conhecimento das outras culturas; e devemos especialmente reconhecer que somos uma cultura possível entre tantas outras, mas não a única (LAPLANTINE, 2013, p. 13).

Reconhecer em Outro indivíduo (ou em um conjunto deles) suas peculiaridades e diferenças é definidora da antropologia. É na prática desse estranhamento que nos afirmamos como sendo, da mesma maneira, o Outro.

No cinema, sobretudo no documentário, para colocar o Outro em cena ou como diria Claudine de France, "os estudo do homem (o Outro) pelo filme significa não somente o estudo do homem filmável - suscetível de ser filmado -, mas, igualmente, o homem filmado, tal como aparece colocado em cena pelo filme" (2000, p. 18, grifo nosso). O Outro filmado possui um objeto fílmico: a imagem do homem. Na unidade e na diversidade das maneiras como coloca em cena suas ações, seus pensamentos e seu meio ambiente, isto é, sua cultura. Nesse sentido, não é diferente da citação mencionada por Laplantine, em que reconhecer o Outro nasce do estranhamento desse encontro. Portanto, o filme documentário e a etnografia possuem os mesmos traços.

Grosso modo, respondendo à pergunta acima formulada, quais requisitos deve cumprir um filme como discurso antropológico? Acredito que todo filme que nos aproxime ao entendimento "do outro eu", que nos aproxime as diferentes 
maneiras de ver o mundo dos diferentes grupos humanos, às diferentes formas de vida, aos padrões de cultura, às linguagens, aos ritos e aos conflitos, às contradições, aos traços visíveis que o mundo deixa na celuloide. Resumindo aos Estudos de Caráter Cultural Contemporâneos.

Antes de finalizar, gostaria de afirmar que este primeiro ensaio tem em sua inicial pretensão tentar pavimentar algumas considerações epistemológicas e metodológicas que a antropologia do cinema urge necessária para seus futuros rumos. Nesse sentido, tentei estabelecer diálogos para utilizar a narrativas cinematográficas como base empírica na pesquisa antropológica.

\section{REFERÊNCIAS}

ALBERA, François. Pierre Francastel, le cinéma et la filmologie. Cinémas. 192-3. 2009. pp. 287316. DOI: 10.7202/037557ar.

Éléments et structures du langage figuratif. Annales de la faculté des lettres de l'Université de Bari, 1965).

AUMONT, Jacques. A imagem. Campinas, SP: Papirus Editora, 1993.

Campinas, SP: Papirus Editora, 1995.

A estética do filme.

AUMONT, Jacques e MARIE, Michel. Dicionário teórico e crítico de cinema. São Paulo: Papirus, 2007.

BARTHES, Roland. A Morte do Autor. In: BARTHES, Roland. O Rumor da Língua. São Paulo: Martins Fontes, 2004.

BAZIN, André. O cinema, São Paulo: Brasiliense, 1991.

BENEDICT, Ruth. A ciência do Costume. In: BENEDICT, Ruth. Padrões de cultura. Lisboa: Ed. Livros do Brasil, p. 13-32, 2000.

O Crisântemo e a Espada. São Paulo: Perspectiva, 1972. p. 14-15.

BENEDICT, Ruth; MEAD, Margaret; SAPIR, Edward; organização Celso Castro. Cultura e personalidade. tradução Maria Luiza X. de A. Borges. Rio de Janeiro: Zahar, 2015.

DIDI-HUBERMAN, Georges. S'inquiéter devant chaque image entretien avec Georges DidiHuberman. Publiée le 11 octobre 2006 Catégorie Entretiens. Mots-clés Georges Didi-Huberman, Documenta 12. Disponível na Internet $<\mathrm{http}: / /$ www.vacarme.org/article1210>. Acesso em: 02 set. 2017.

DUBOIS, Philippe. O Ato Fotográfico. São Paulo: Papirus Editora, 1993. p. 33.

EISENSTEIN, Sergei. A forma do filme. Rio de Janeiro: Jorge Zahar Ed., 1990.

FOUCAULT, Michel. O que é um autor? In: Ditos e escritos III: Estética: literatura e pintura, música e cinema. Tradução de Inês Barbosa. Rio de Janeiro: Forense, 2011.

FRANCASTEL, Pierre. L'image, la vision et l'imagination. De la peinture au cinéma, Paris, Denoël/Gonthier, 1983.

FRANCE, Claudine de. Cinéma et Anthropologie, Paris (EMSH), 1989.

'Antropologia Fílmica - Uma

Gênese difícil, mas promisora. In: Do filme etnográfico à antropologia fílmica. Trad. Marcius S. Freire. Campinas, SP, Editora da Unicamp, 2000.

GEERTZ, Clifford. A interpretação das culturas. RJ, LTC, 1989.

O Saber Local - Novos Ensaios em Antropologia Interpretativa. Petrópolis, Vozes, 1997.

GOLDMAN, Márcio; NEIBURG, Frederico. Antropologia e Política nos Estudos de Caráter Nacional. Anuário Antropológico. Rio de Janeiro: Tempo Brasileiro, v. 97, 1999. p. 103-138.

HÍKIJI, Rose Satiko Gitirana. Antropólogos vão ao cinema - observações sobre a constituição do filme como campo. Cadernos de Campo (São Paulo, 1991), São Paulo, v. 7, n. 7, p. 91-113, mar. 1998. ISSN 2316-9133. Disponível em: <http:// 
www.revistas.usp.br/cadernosdecampo/article/ view/52606/56520>. Acesso em: 02 ago. 2017. doi: http://dx.doi.org/10.11606/issn.2316-9133. v7i7p91-113.

JULLIER, Laurent e MARIE, Michel. Lendo as imagens do cinema, São Paulo; SENAC, 2009.

KRACAUER, Siegfied. Teoría del cine: la redención de la realidad física. Barcelona: Ediciones Paidós Ibérica S.A, 1989 [1960].

LAPLANTINE, François. Aprender Antropologia. Trad. Marie-Agnèz Chauvel, São Paulo: Brasiliense, 2003 [1943]

LEROI-GOURHAN, André. Cinéma et sciences humanas - Le filme ethnologique existe-t-il?, in Revue de géographie humaine et d'ethnologie, Paris, $\mathrm{N}^{\circ} 3$, 1948. p. 42-50.

MALINOWSKI, Bronislaw. Argonautas do pacifico ocidental: Um relato do empreendimento e da aventura dos nativos nos arquipélagos da Nova Guiné melanesia. São Paulo: Abril Cultural, 1976. 436 p. (Pensadores(os); v.43).

MEAD, Margaret. National Character. In: Anthropology Today: Selections (Sol Tax, org.).Chicago: Chicago University Press, 1962. pp. 396-421.

MEAD, Margaret; MÉTRAUX, Rhoda (ed.) The Study of Culture at Distance, Chicago, The University of Chicago Press, 2000 [1953].

MENEZES, Paulo. Representificação: as relações (im)possíveis entre cinema documental e conhecimento. Revista Brasileira de Ciências Sociais, Anpocs [online]. 2003, vol.18, n.51, pp.87-98. ISSN 1806-9053. http://dx.doi. org/10.1590/S0102-69092003000100007.

MORIN, André. El cine o el Hombre imaginário. Ensayo de antropologia sociológica. Paidós. 2001 [1956]. Barcelona.

SAMAIN, Etienne. As "Mnemosyne(s)" de Aby Warburg: Entre Antropologia, Imagens e Arte. Revista Poiésis, n 17, p. 29-51, jul. de 2011.

SORLIN, Pierre. Sociología del cine: la apertura para la historia del mañana; tr. Juan José Utrilla, 1985.

WRIGHT, Mills. A imaginação sociológica. $2^{\mathrm{a}}$ Edição. Rio de Janeiro: Zahar Editores, 1969.

\author{
.
}

